\title{
ALFREDO GUISADO E A GALIZA NO PERIÓDICO REPÚBLICA
}

\author{
AlfREDO GUisAdo AND GALIZA IN THE PAPER \\ REPÚBLICA
}

\section{Fernando de Moraes Gebra*}

Resumo: Como diretor da página literária do jornal República desde 1943 e diretor adjunto desse periódico desde 1954, Alfredo Pedro Guisado (1891-1975) desenvolveu a crítica literária e escreveu textos sobre aspectos da literatura e da cultura galegas. O presente artigo centra-se nas relações dialógicas estabelecidas pela poética de Alfredo Guisado com o emergente sistema literário galego, consolidado pelo grupo das Irmandades da Fala e pela Xeración Nós. Com base no conceito de dialogismo de Mikhail Bakhtin, segundo o qual em todo enunciado ressoam pelo menos duas vozes, analiso o discurso ensaístico acerca da história e da literatura galegas em alguns textos publicados no periódico República.

Palavras-chave: Alfredo Guisado; Xeración Nós; Dialogismo.

AвSTRACT: As a literary section director in the paper República, and as an adjunct director in this paper since 1954, Alfredo Pedro Guisado (1891-1975) developped the literaty criticism and wrote texts about Galician literature and culture. The present paper focuses on dialogical relationships established by Alfredo Pedro Guisado's poetry with the emergent Galician literary system, consolidated by the groups Irmandades da Fala and Xeración Nós. Based on the concept of dialogism by Mikhail Bakhtin, I analyse the essayistic discourse about Galician History and Literature in some texts published in the paper República.

KEYwords: Alfredo Guisado; Xeración Nós; Dialogism.

\footnotetext{
"Doutor em Letras pela Universidade Federal do Paraná (UFPR); Professor Adjunto VI da Universidade Federal da Fronteira Sul (UFFS), no Curso de Licenciatura em Letras, área de Teoria Literária e Literaturas de Língua Portuguesa, e no Mestrado em Estudos Linguísticos, área de Práticas Discursivas e Subjetividades; membro do Grupo da ANPOLL Imaginário, representações literárias e deslocamentos culturais e do Grupo Interdisciplinar de Estudos Pessoanos e do Modernismo (IEMO), da Universidade Nova de Lisboa. Email: fernandogebra@yahoo.fr
} 


\section{INTRODUÇÃO}

A obra de Alfredo Pedro Guisado (18911975), que também escreveu sob pseudônimos como Refaldo Brila, Pedro de Menezes, Alfredo Abril, João da Lobeira e Domingos Dias Santos, abrange um arco temporal que vai de janeiro de 1912, aquando da publicação do seu primeiro poema "Noites de inverno", no periódico agrarista galego $E l \mathrm{Tea}$, até 30 de novembro de 1975, data do seu falecimento, ocasião em que ainda havia inéditos, publicados em 1996 numa edição organizada por Fernandes Camelo e intitulada Tempo de Orpheu II.

Ao considerar o vasto arco temporal em que se produz o discurso poético e crítico de Alfredo Guisado, devem-se examinar as metamorfoses desse discurso que não permanece homogêneo ao longo de mais de seis décadas. Intérprete das conjunturas sócio-históricas portuguesa e galega, Alfredo Guisado passa por várias metamorfoses no seu discurso, o que invalida determinadas leituras que a historiografia e a crítica literárias portuguesas costumam fazer acerca de sua obra, circunscrevendo-a apenas ao chamado tempo de Orpheu. Ao circunscrever o autor a um determinado tempo, reduz-se a complexidade da sua obra. Além disso, costuma-se ler a sua poética como se fosse tributária ou dependente de Fernando Pessoa e Mário de Sá-Carneiro, leitura equivocada feita por João Gaspar Simões e seguida por Apolinário Lourenço, conforme dados manejados por Carlos Pazos Justo (2015, p.102).

O Colóquio Internacional 100/Exílio \& Centauro: Modernismo em Revista(s), embora tenha homenageado essas duas importantes revistas, também pouco estudadas pela historiografia literária portuguesa - mais centrada nos aspectos vanguardistas que consegue encontrar em Orpheu, de 1915, e Portugal Futurista, de 1917 - incide sobre as relações interdiscursivas e interartísticas presentes em periódicos literários. A interdiscursividade "é inerente à constituição do discurso" (FIORIN, 1999, p.35), pois toda linguagem "está impregnada de relações dialógicas" (BAKHTIN, 2015, p.209). Dito de outra forma, todo discurso, seja qual for sua materialização, constrói-se a partir de discursos precedentes, estabelecendo com eles relações contratuais ou polêmicas. Em todo período histórico, existe uma espécie de espírito unificador entre artes, ciências e filosofia (ROSENFELD, 1996, p.75-6), de modo que a análise do discurso literário deve considerar as relações interdiscursivas com as outras artes. No caso específico dos grupos Orpheu e Nós, seus artistas apresentam uma consciência dessas relações dialógicas entre as diversas artes, aspecto examinado no presente trabalho.

Tendo em vista as relações interartísticas presentes tanto em Orpheu como em Nós, e as relações interdiscursivas que a poética de Alfredo Guisado estabelece com o emergente sistema literário galego do período das Irmandades da Fala e da Xeración Nós, resolvi, pois, destacar a importância do "mais injustamente esquecido dos poetas de Orpheu" (LOPES, 1966, p.715) para a configuração do sistema literário galego. Este começa a ser sistematizado com os autores do Rexurdimento na segunda metade do século XIX, como Rosalía de Castro, Curros 
Enríquez e Eduardo Pondal, e consolida-se graças aos grupos das Irmandades da Fala, que fundam a revista A Nosa Terra em 1916, e da Xeración Nós, relacionada à revista Nós, cujo primeiro número data de 1920.

A perspectiva marcadamente dialógica presente na revista Orpheu e no grupo das Irmandades da Fala permitiu a aproximação de intelectuais portugueses e galegos. Nesse contexto, Alfredo Guisado - filho e neto de emigrantes galegos que passaram a administrar os cinemas lisboetas e o restaurante Irmãos Unidos, no Rossio - em suas férias na aldeia de Pías e no balneário de Mondariz, conheceu muitos intelectuais galegos com os quais travou profundos laços de amizade. Foi no balneário de Mondariz que o jovem Alfredo Guisado conheceu, provavelmente em 1913, o artista polígrafo Alfonso Daniel Rodríguez Castelaoi, responsável pelo desenho da capa do livro Xente d'a aldea, publicado em 1921.

Os grupos das Irmandades da Fala e da Xeración Nós apresentam uma dimensão multicultural, abrangendo várias áreas do conhecimento-História, Geografia, Literatura, Etnografia - e uma preocupação nacionalista, que se encontra na escrita de textos do mais variados gêneros do discurso em língua galega. Na segunda metade do século XIX, a língua galega era usada pelos poetas do Rexurdimento para a escrita de textos poéticos, não sendo estendida para a prosa de

${ }^{1}$ Conforme nota de Carlos Pazos Justo, "A relação de Castelao com o estabelecimento termal dos Peinador remonta, segundo Miguel Anxo Seixas (Seixas 2000: 14 e ss.), ao ano 1913, em que dá uma conferência, depois publicada em La Temporada; desde 1915, por exemplo, o Balneário terá quadros de sua autoria” (2015, p.272). ficção e o ensaio. Com as Irmandades da Fala, esses gêneros em prosa passam a ter grande importância para a divulgação dos estudos referentes aos aspectos culturais da Galiza.

\section{A Galiza nas páginas literárias de REPÚBLICA}

Alfredo Guisado teve grande participação no meio político português junto aos democratas. Fora do campo político português a partir de 1926 por apresentar ideologias adversas àquelas defendidas pelo novo regime, Guisado passou a atuar no jornal República, único órgão de oposição tolerado pelo governo de António de Oliveira Salazar. Em 12 de fevereiro de 1943, assumiu a direção de uma página literária, dedicada a comentar semanalmente os livros que iam sendo publicados, e em 3 de abril de 1954, tornou-se diretor adjunto do periódico2. Além das recensões críticas acerca de obras literárias, Guisado deixou, nas páginas de República, inúmeros textos de crítica literária, com elementos ensaísticos e memorialísticos, acerca das literaturas portuguesa e galega. Dos textos sobre a literatura e a cultura galegas, julgo fundamentais: "Comentário", de 5 de março de 1943; "Comentário", de 25 de janeiro de 1944; "Evoca-se um genial artista galego", de 3 de fevereiro de 1958. Esses textos incidem, respectivamente, sobre a história da literatura galega, a poética de Rosalía de Castro e a produção artístico-literária de Castelao,

\footnotetext{
${ }^{2}$ Minha investigação de Pós-Doutoramento consistiu, entre outros aspectos sobre os "esquecidos" de Orpheu, no levantamento e tratamento desses textos de crítica literária publicados desde 1943, quando Alfredo Guisado passou a se ocupar da página literária desse periódico.
} 
fundamentais para a compreensão das relações interculturais Portugal e Galiza, no campo literário.

No "Comentário", de 5 de março de 1943, cruzam-se vários discursos de renomados historiadores e críticos literários, como Eugenio Carré Aldao, Saralegui y Medina, Teófilo Braga, Blanco García e Leite de Vasconcelos. Todos esses discursos apontam para a valorização de uma língua, uma cultura e uma literatura esquecidas e desprezadas tanto por castelhanos como por portugueses. Esses discursos contrapõem-se a outros discursos: "Há muita gente que supõe, ouvindo falar daquela região e do seu povo, que apenas servem para ser ridicularizados e escarnecidos" (GUISADO, 1943, p.3); "Efectivamente, por motivos que não se compreendem bem, tem-se rodeado a palavra galego do desprezo e do ridículo" (GUISADO, 1943, p.3). Os discursos que desvalorizam a língua e a cultura galegas são trazidos para dentro dos enunciados de Alfredo Guisado para serem deslegitimados. Deixa-se no anonimato, no indefinido o "muita gente", como forma de intensificar a desqualificação de seus discursos de escárnio em relação a uma cultura tão importante como é a galega.

A "razão errada dessa maneira de ver" a cultura galega como sinônimo de escárnio é combatida nos enunciados de Alfredo Guisado e no discurso citado de Eugenio Carré Aldao, segundo o qual essa imagem equivocada feita acerca da Galiza e dos galegos tanto em Castela como em Portugal são oriundas de motivações históricas:

Castela, vendo-se privada de Portugal, considerava a Galiza unida, pela raça e pela língua, ao reino separado e fazia-a objecto do seu desprezo e mísera vingança [...] Portugal, por sua vez, considerava a Galiza território que devia fazer parte integrante do Estado (GUISADO, 1943, p.3).

Após opor-se ao discurso de outrem, daqueles que falam "da Galiza de um modo que não é elogioso" e dos "galegos de uma maneira que não é para louvar", Alfredo Guisado destaca a importância da língua galega na formação da cultura portuguesa e do sistema literário português. São tomados de empréstimo os discursos de Saralegui y Medina e de Teófilo Braga para referendar o fato de as produções literárias anteriores ao século XV em Portugal terem sido escritas em "galego primitivo" e, ainda, que "a língua galega era a preferida para a composição poética das côrtes em que se imitava a poesia trovadoresca, tão delicada na sua casuística sentimental".

Antes das revoltas irmandiñas, o galego era língua de prestígio internacional. Foi o acordo dos camponeses com os reis católicos com o intuito de se livrarem do jugo dos fidalgos que provocou a quase extinção da classe fidalga na Galiza, com a destruição de muitos dos seus castelos, e a anexação da Galiza aos reinos de Castela e Aragão, obscurecendo a produção artístico-cultural em língua galega. São os denominados "séculos escuros": "essa literatura durante longos anos emudeceu, ou pelo menos, não se manifestou dentro dela quem quer que fosse, de modo a que merecesse especial referência, porque submetida" (GUISADO, 1943, p.3). A submissão ao jugo castelhano começa a se modificar no contexto das independências das então colônias 
hispano-americanas, conforme declara Carré Aldao, citado por Guisado, segundo o qual se trata de um período em que a Galiza passa a ter vida própria, com grande produção artístico-cultural, motivada também pela geração chamada de Precursores, com "livros, folhetos, jornais e folhas soltas na língua do país" (GUISADO, 1943, p.3).

Na sequência do seu texto acerca da história da literatura galega, Alfredo Guisado prescinde de citações de historiadores e críticos literários, citando apenas - e muito rapidamente - Blanco García e Carré Aldao, para referendar a sua opinião acerca da poética de Rosalía de Castro. Embora Guisado reforce certas metáforas que a crítica literária utilizou para caracterizar a poética de Rosalía "encantadora ternura", "delicado amor à sua terra", "embala o povo na sua ternura", "doce cantar" - utiliza a metáfora do discuso do crítico Carré Aldao, que se refere ao poemário Cantares gallegos (1863) como "grito de guerra de um povo subjugado" (GUISADO, 1943, p.3).

No contexto de produção do discurso crítico de Alfredo Guisado, vigoravam imagens de uma poética rosaliana de ternura, docilidade e amor à terra, atributos desejados ao sujeito lírico feminino. Não se enfatizava o discurso contestatário presente na metáfora de Carré Aldao de "grito de guerra de um povo subjugado", pois o contexto de produção do discurso de Guisado se situa "Antes da revisión que sofreu a obra de Rosalía desde a análise de estudiosas e estudiosos como Catherine Davies, Francisco Rodríguez, Pilar Pallarés, Pilar García Negro, etc..." (SÁNCHEZ \& SAZ, s/d, p. 131). Nesse revisionismo, recupera-se a "estrofe maldita" do poema que o marido de Rosalía, Manuel Murguía, ao publicá-lo no livro Los precursores (1866) intitulou "Adiós, ríos; adiós, fontes".

Por xiadas, por calores

Desde qu' amañece ó día

Dou á terra os meus sudores

Mais canto a terra cría

Todo todo e dos señores. (ALONSO, 2012, s/p.)

No ensaio "O primeiro poema galego de Rosalía”, o autor Manuel Rodríguez Alonso fornece uma explicação sobre a retirada da chamada "estrofa maldita" do poema de Rosalía, aquando da publicação do livro Los precursores (1885), de Murguía, e que seguirá nas edições posteriores de Cantares: "O historiador Xosé Antonio Durán (2012) [...] atribúe esta supresión a que nela Rosalía defendería concepcións sobre a propiedade da terra propias do socialismo utópico, que non lle parecerían acaídas a Murguía" (ALONSO, 2012, s/p).

Como se vê, permaneceu no imaginário de críticos literários e leitores a concepção de uma poética rosaliana marcada pela ternura e docilidade. No discurso de Guisado, há um interessante contraponto das figuras literárias de Rosalía e Curros Enríquez, expresso nas seguintes construções metafóricas:

Rosalia embala o seu povo na sua ternura, no seu doce cantar como uma mãe que tenta defender o filho, apertando-o contra o peito, com receio de que lho levem ou de que o maltratem. Curros defende-o, chicoteando os que o tentam prejudicar, os que o querem escravizar (1943, p.3). 
De acordo com Mikhail Bakhtin, "orientando para o seu objeto, o discurso penetra neste meio dialogicamente perturbado e tenso de discursos de outrem, de julgamentos e de entonações" (1998, p.86). Nessa perspectiva, no discurso crítico de Alfredo Guisado acerca da poética de Rosalía de Castro ressoam vozes de uma tradição crítica que coaduna discursos patriarcais, segundo os quais cabe à mulher uma posição passiva, representada pela imagem da mãe "que tenta defender o filho, apertando-o contra o peito", enquanto ao pai cabe uma postura combativa, de luta armada, ideologia utilizada para descrever metaforicamente a poética de Curros Enríquez, na ação de chicotear "os que tentam prejudicar" o povo, os que "o querem escravizar". Conforme Sánchez e Saz, Rosalía de Castro "rompía todas as normas que a sociedade (im)puña ás mulleres: facía literatura, literatura feminista, desde unha óptica galega e, ademais, en galego" (s/d, p.119).

Embora reitere as imagens cristalizadas no discurso da crítica literária acerca de Rosalía de Castro, como "sentimentalismo adorável", "ternura especial", "encantadora suavidade”, "amor à terra”, Alfredo Guisado, em texto publicado em 25 de janeiro de 1944, acrescenta a essas imagens o seguinte enunciado: "Para defender os seus, não hesita em atacar, em agredir aqueles que sabe que não têm pela sua pátria e pela sua gente o mesmo carinho que ela sente." (1944, p.3. Destacados meus). Ressoa nesse enunciado o discurso de Alfredo Guisado - proferido em 26 de fevereiro de 1915, registrado e publicado por Alejo Carrera em 12 de março no periódico agrarista-sindicalista El Tea -, no qual se vislumbra a denúncia social aos caciques: "esos otros hijos bastardos, degenerados y malditos que se llaman caciques" (1915, p. 2). A poética de Rosalía é lida, também, a par das imagens cristalizadas, como uma lira combativa, como se nota pelos verbos "atacar" e "agredir" nesse texto, e também no texto anterior, no discurso citado de Carré Aldao, nas expressões "grito de guerra de um povo subjugado" (GUISADO, 1943, p.3). Dessa forma, nota-se no discurso crítico de Guisado o prenúncio do revisionismo crítico a que será levada a obra de Rosalía de Castro em décadas posteriores.

Apesar de ressaltar nesse ensaio de 1944 a figura e a poética de Rosalía de Castro, com destaque aos Cantares gallegos, Alfredo Guisado enfatiza a importância das mulheres galegas na literatura:

É também curioso saber-se que, na Galiza, a mulher tem dado à literatura da sua terra e até à da Espanha alguns nomes que se admiram, como Pardo Barzán, Sofia Casanova, Manuela Carbonero, Francisca Isla Losada, Narcisa Pérez, Filomena Dato, Eulália de Lians, Marcelina Soto, Elvira Luna del Castillo, a pensadora de fama universal Concepción Arenal, etc. (1944, p.3).

De forma semelhante ao texto de 1943, neste também incorporam-se discursos outros na filigrana discursiva do ensaísta, para referendar a importância da língua galega. No contexto de produção dos Séculos Escuros, o Padre Sarmiento assim se expressou, como se vê no discurso citado no 
enunciado do texto em exame: "as línguas vulgares que somente se falam e não se escrevem são quase eternas" (1944, p.3). Já Castelar ressalta o imagotipo presente no século XIX, segundo o qual a língua galega é considerada "tão apropriada para expressar os sentimentos". E, por fim, Alexandre Herculano, ressalta o imagotipo da fraternidade luso-galaica, também presente no poema de Guisado " $\mathrm{El}$ y Ela", de Xente d'a aldea: "o português não é mais do que o galego civilizado e aperfeiçoado." (1944, p.3).

Para referendar sua compreensão acerca da poética rosaliana, Alfredo Guisado vale-se de discursos precedentes como os de Emilia Pardo Bazán, Carré Aldao e Otero Pedrayo. O primeiro é um tanto problemático, haja vista a rivalidade pública e notória de Pardo Bazán com o casal Rosalía-Murguía. Com posição contrária à escrita em língua galega dos poetas do Rexurdimento, Pardo Bazán emite o seguinte juízo crítico acerca da poética rosaliana: "é o melhor que Rosalia produziu, o mais sincero da poesia galega e o que mais copia a fisionomia tradicional e pitoresca do país" (GUISADO, 1944, p.3). Sinceridade, tradicionalismo e pitoresco: é o que enxerga Pardo Bazán numa poética muito mais complexa, e com forte acento de combate, como apresentei linhas atrás. Para Carré Aldao, a poética de Rosalía "é alguma coisa mais do que o rumor cadenciado das palavras" (GUISADO, 1943, p.3). E mesmo Otero Pedrayo, em um discurso citado com alta carga metafórica, destaca aspectos de suavidade, ternura e harmonia na poética rosaliana: como se entra, ao anoitecer, num jardim de um palácio abandonado, onde as janelas se encontram fechadas, cujos donos há muito desapareceram, mas onde os jasmineiros continuam a florescer, jardim onde uma branca e suave mão de uma senhora galega desenhou, como num tema musical, o harmonioso contorno das alamedas... (GUISADO, 1944, p.6)

Outras figuras de proa da literatura galega mencionadas nos ensaios de Alfredo Guisado são "Añon, Pondal, Carvajal, Murguía, e tantos outros que encheram toda uma época literária" (1943, p.3), no século XIX, e Amado Carballo, Ramón Cabanillas,Vicente Risco e Castelao, no século XX. Sobre Amado Carballo, destacam-se as seguintes palavras: "o mais modernista dos poetas daquela região e que a morte arrebatou em plena mocidade" (GUISADO, 1943, p.3); sobre Ramón Cabanillas: "um dos maiores poetas da moderna geração, que, apesar de escrever só em galego, foi eleito sócio da Academia espanhola" (GUISADO, 1943, p.3). De Vicente Risco, transcreve um trecho da sua Teoría d'o nacionalismo galego, publicado no periódico La Región, de Ourense, em 1920.

Mas, apesar do ódio com que o perseguem, o galego vive, falam-no as quatro quintas partes do povo e encontra-se hoje numa das suas épocas de maior florescimento literário, convertendo-se em instrumento de expressão científica e produção filosófica (GUISADO, 1943, p.3).

E, por fim, acerca do amigo Castelao, autor da capa de Xente d'a aldea, Alfredo 
Guisado não economiza elogios, destacando o aspecto polígrafo desse autor que, como Vicente Risco, foi uma das figuras de proa da Xeración Nós.

Castelao, escritor, pintor, caricaturista, o grande desenhador das dores dos seus compatriotas, o grande intérprete das reivindicações da gente da sua terra, em cujos quadros se adivinha a sua alma de poeta e em cujos livros se

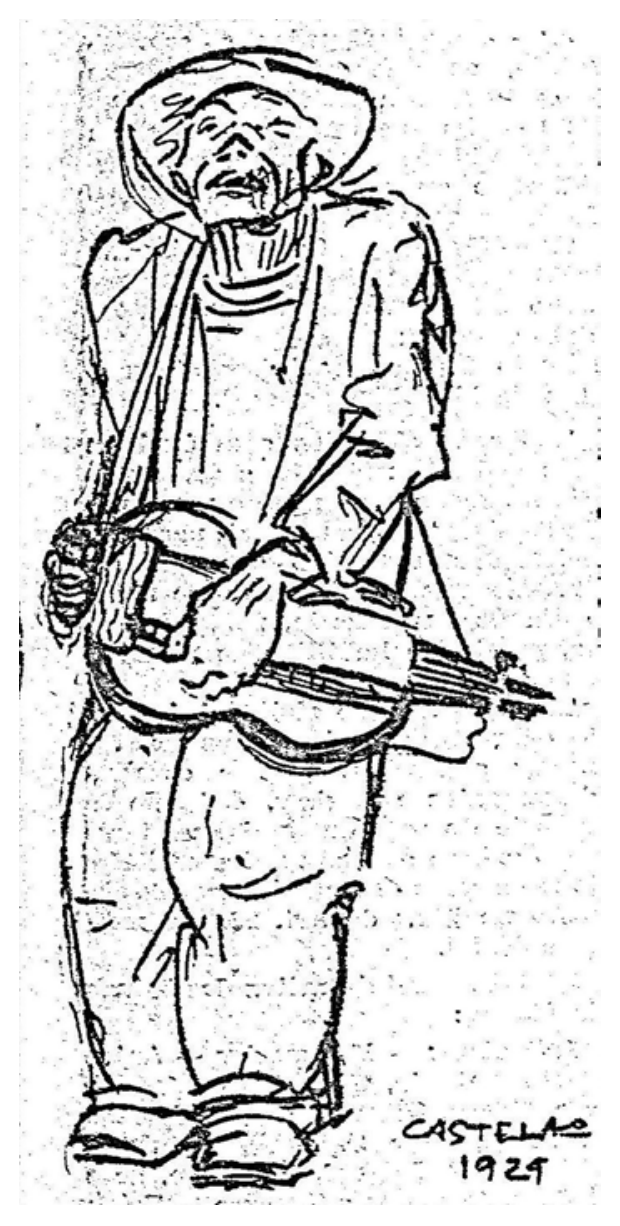

encontram vestígios dos seus pincéis de mestre (GUISADO, 1943, p.3).

As expressões "o grande desenhador das dores do seus compatriotas" e "o grande intérprete das reivindicações da gente da sua terra" ganham outros contornos metafóricos em texto escrito e publicado oito anos após o falecimento de Castelao.

Misto de discurso memorialístico, relato autobiográfico e crítica de arte, o texto "Evoca-se um genial artista galego", estampado na República em 3 de fevereiro de 1958, apresenta o seguinte subtítulo: "Um desenho inédito de Castelao feito há 28 anos num 'café' de Pontevedra e algumas notas sobre o inesquecível músico, pintor e escritor que foi um dedicado amigo de Portugal" (GUISADO, 1958, p.1). Um dos textos de Alfredo Guisado de maior penetração analítica, parte de uma memória - a viagem que o autor fez em 1929 com António Ferro por terras galegas e o encontro com Castelao num café de Pontevedra - para discutir o processo de composição do desenho "O cego na sanfona", estampado naquele mesmo número de República, as temáticas recorrentes na obra pictórica e literária de Castelao, e suas principais características, tanto estéticas como ideológicas.

Por ocasião dos jogos-florais luso-galaicos, idealizado por Alfredo Guisado desde 1919, e com a participação e o interesse do então jornalista António Ferro, este último "fôra encarregado pelo jornal em que então trabalhava, de ir à Galiza ouvir algumas das pessoas mais em evidência a fim de saber a sua opinião acerca desse certame" (GUISADO, 1958, p.1). Como tinha assuntos pessoais a tratar, Alfredo Guisado resolveu acompanhar 
o então amigo e apresentar-lhe muitos intelectuais galegos: “[...] e aproveitava a ocasião para o apresentar a velhos amigos e camaradas que lá tinha, alguns dos quais a morte já levou e outros que ainda tenho, pois, felizmente, pertencem ao número dos vivos" (GUISADO, 1958, p.1). Por esse discurso, nota-se que mesmo em 1958, distanciado do campo político e literário galegos, Alfredo Guisado manteve relações com a intelectualidade galega. Num café em Pontevedra, Ferro e Guisado encontram Alfonso Daniel Rodriguez Castelao e essa cena é motivo de rememoração, pois foi nesse dia que o artista plural desenhou "O cego da sanfona":

Momentos depois, subitamente, acercou-se da nossa mesa um velho cego, mal trajado, que, servindo-se duma sanfona que trazia a tiracolo, começou a massacrar os nossos ouvidos com uma determinada música que arranhava no mencionado instrumento. Castelao que viu o cego, certamente por motivos que adiante explicarei, pediu uma folha de papel, tirou do bolso um lápis e, com grande rapidez, desenhou tal qual era o velho que estava com a sanfona junto da nossa mesa. Passados momentos, cada um de nós entregou ao cego o que entendeu e o velho sumiu-se, ao mesmo tempo que Castelao se preparava para rasgar o desenho que fizera. Intervim então, pedindo-lhe que o datasse e assinasse e que mo desse. Ele acedeu. Guardei-o na minha pasta como uma relíquia. É o que hoje nestas colunas acompanha estas palavras (GUISADO, 1958, p.9).
O fragmento transcrito constitui um discurso memorialístico que aponta para o processo composicional do desenho estampado em 1958 nas páginas de República. O lápis como instrumento de trabalho e a representação de cegos sempre em primeiro plano tanto nas telas como nos desenhos constituem aspectos da vida e da obra de Castelao que Alfredo Guisado destaca no seu texto.

Ele sentia bem que a doença o ia espreitando a cada momento e a cada passo, pois na sua admirável obra de pintor, marcava sempre os cegos num primeiro e mais destacado plano, aqueles cegos que arrastam os corpos nas romarias ou nas estradas, estendendo as mãos trêmulas e indecisas para saírem da sombra em busca da luz ou duma piedosa esmola, aqueles cegos a que chegou a chamar seus companheiros. E a cegueira que se ia aproximando, não lhe permitiu que o seu maravilhoso pincel, acostumado a reproduzir a encantada paisagem da sua região e as figuras torturadas dum povo paciente e sofredor, continuasse a deixar na tela o sonho do pintor e a beleza da sua arte (1958, p.9. Destacados meus).

A aproximação da doença que gradativamente lhe afetava a visão fê-lo aproximar-se ainda mais dos cegos, a ponto de chamá-los "seus companheiros". Desde as telas de 1911 que foram doadas ao Balneário de Mondariz e que hoje pertencem ao Museu de Pontevedra, com "os cegos num primeiro e mais destacado plano" a arrastarem "os corpos nas romarias ou nas estradas" (1958, p.9) na busca de uma luz e de uma esmola, até os desenhos feitos a lápis em obras como Nós e Cousas, Castelao costuma adotar em sua 
obra a "encantada paisagem da sua região" e "as figuras torturadas dum povo paciente e sofredor" (GUISADO, 1958, p.9). As paisagens geográfica e humana encontram-se, pois, imbricadas, procedimento estético também presente na obra de Alfredo Guisado, notadamente em Rimas da noite e da tristeza (1913) e Xente d'a aldea (1921). Não se pode esquecer que Castelao foi um dos principais interlocutores de Alfredo Guisado, a ponto de ser possível afirmar as relações dialógicas que as obras de um compartilham com as obras do outro. No discurso de Alfredo Guisado, transcrito por Alejo Carrera, no poema "Castillo d'o Sobroso" e em outras tantas intervenções poéticas e políticas do autor de Mais alto nas imprensas portuguesa e galega, nota-se o que o autor destaca acerca da obra Nós (1931), de Castelao:

Serviu-se então do lápis que ora era carinhoso e leve, quando pretendia desenhar a dor dos seus conterrâneos, ora causticaste e duro quando tinha o intuito de, com ele, castigar os que os maltratavam. O álbum "Nós" é uma verdadeira maravilha de traços e de intenção. Cada uma das figuras que, nesse álbum, se encontra, está inteiramente certa. Dá a impressão de que foram arrancadas à realidade e presas ali, nesses belíssimos desenhos, no desejo de patentear bem tudo quanto tinham de sofrimento e de tortura os perseguidos e de má-vontade, perfídia e maldade, os perseguidores (1958, p.9. Destacados meus).

O fragmento supracitado constrói-se a partir de antíteses. Por um lado, encontra-se o lápis, metonímia do processo criativo, que se apresenta "carinhoso e leve" ao desenhar "a dor dos seus conterrâneos", o "sofrimento" e a "tortura" dos perseguidos - entendem-se os trabalhadores agrícolas - ou "causticante e duro", quando pretende "castigar o que os maltratavam", com o intuito de "patentear bem tudo quanto tinham [...] de má vontade, perfídia e maldade, os perseguidores" - referentes aos caciques, os exploradores que vilipendiavam os agricultores com altos impostos.

O lápis, ora "carinhoso e leve", ora "causticante e duro", assume características de combate e de luta social próximos ao da foice, imagem-símbolo de resistência no poema "Castillo d'o Sobroso" e no conto "A lareira. O tio Xan", de Guisado. A leitura feita por Alfredo Guisado acerca da obra de Castelao destaca esse discurso de resistência à opressão dos caciques e do governo de Francisco Franco, responsável pela cruenta Guerra Civil Espanhola. Ao tratar das coleções Galiza mártir (1937), Átila em Galiza (1937) e Milicianos (1938), o ensaísta assim se refere ao discurso estético-ideológico presente na estrutura composicional dessas obras: “[...] marcam uma forte personalidade de artista e de lutador que não abandona a barricada quando entende ser sua obrigação lutar para vencer" (1958, p.9. Destacados meus).

O pincel-foice, instrumento de luta no intuito de diminuir as iniquidades sociais, acompanha a obra pictórica e literária de Castelao.

Com a sua pena, Castelao não deixou um instante também de castigar aqueles que maltratavam a sua terra e a sua gente. O seu interessante livro "Cousas" é um rosário de contos que os galegos rezam sempre na leitura das belas letras. 
(...) Nas Constituintes da República Espanhola e quando, como deputado, de novo foi reeleito, bateu-se sem o mais leve desfalecimento pela liberdade do povo galaico (GUISADO, 1958, p.9. Destacados meus).

Alfredo Guisado destaca, ao longo do seu ensaio memorialístico, a estreita vinculação entre os projetos estético e ideológico de Castelao, como se verifica na metáfora dos traços carinhosos e leves utilizados para a representação dos marginalizados e explorados, e dos traços causticantes e duros destinados às classes dominantes, principalmente os "perseguidores". De maneira correlata, Anxo Gómez Sánchez e Mercedes Queixas Zas, quando tratam da "perfecta simbiose entre as diferentes artes (literaria e plástica)" a confirmar "a criación dun xénero novo, con marca de orixe natural castelaniana", que é o livro Cousas (1926), destacam a atitude do narrador a oscilar entre uma "actitude crítico humorística ao tratar o mundo dalgunha clase social como a fidalguía" e a "ternura e complicidade co mundo dos pícaros, dos mariñeiros e cos marxinados galegos" (SANCHEZ \& ZAS, s/d, p.224).

Além das contribuições artísticas, Castelao destacou-se nos estudos etnográficos acerca dos cruzeiros. "Onde hai un cruceiro houbo sempre un pecado, e cada cruceiro é unha oración de pedra que fixo baixar un perdón do Ceo, polo arrepentimento de quen o pagou e polo gran sentimento de quen o fixo" (CASTELAO, 2015, p.19), escreve o autor numa de suas Cousas, ao destacar a base popular que impregna esses monumentos de pedra: "A Virxe das Angustias, enclavada no reverso de moitas cruces de pedra, non é a Piedá dos escultores; é a Piedade creada polos canteiros" (2015, p.20).

De maneira correlata a Alfredo Guisado, o interesse de Castelao pela tradição popular galega é anterior à década de 1920, marcada pela fundação da Xeración Nós e do Seminario de Estudos Galegos. "Un cruceiro - ou mellor, un remate de cruceiro-é, de feito, o protagonista dunha das obras", comenta Xosé Carlos Valle Pérez (PÉREZ, 1999, p.5) acerca do desenho de número 19 do álbum Nós "conxunto realizado, como Castelao escribe no prólogo-presentación, entre 1916 e 1918", embora publicado apenas em 1931 (PÉREZ, 199, p.5). Não nos esqueçamos de que o interesse de Alfredo Guisado pela cultura popular galega pode ser percebida nos anos de 1912 e 1913, com os poemas publicados em $\mathrm{El} \mathrm{Tea,}$ e também com as viagens por terras galegas relatadas em carta a Augusto Cunha, especificamente o seguinte fragmento: "lá vi, na catedral, que é sumptuosa, os estandartes que lá deixaram as peregrinações de há muitos séculos" (Destacados meus)3. Ambos os autores, que provavelmente se conheciam desde 1913, por ocasião das reuniões e tertúlias no Balneário de Mondariz, apresentam preocupações semelhantes no que se refere às tradições folclóricas e etnográficas da Galiza, ampliadas com a fundação em 1916 do grupo das Irmandades da Fala.

No caso das preocupações folclóricas e etnográficas de Castelao, apesar de já estar

\footnotetext{
${ }^{3}$ Registro aqui meu agradecimento à Senhora Mafalda Ferro por facultar-me o acesso às cartas de Alfredo Guisado a António Ferro e a Augusto Cunha, que pertencem à Fundação António Quadros. A cota desta carta é: PT/ $\mathrm{FAQ} / \mathrm{AFC} / 01 / 001 / 0516 / 00018$.
} 
presente no seu discurso artístico anterior à década de 1920, começam a ser sistematizadas aquando da sua admissão em 3 de novembro de 1923 no recém-criado Seminario de Estudos Galegos (fundado dias antes, em 12 de outubro). Castelao iniciou, a partir de então, uma investigação etnográfica sistemática acerca dos cruzeiros de pedra. Como bolsista, realizou uma viagem de quatro meses pela região da Bretanha, no noroeste francês, em 1929, e desenvolveu um trabalho entendido como "algo máis que unha simple recompilación de información” (PÉREZ, 2004, p.15). No seu trabalho, com resultados divulgados no Seminario de Estudos Galegos, "[...] non se conformou unicamente con ver, anotar e reproducir. Tamén xulga, interpreta, valora e emite hipóteses, algunhas rechazadas por el mesmo posteriormente" (PÉREZ, 2004, p.15). O discurso crítico de Castelao é enfatizado por Alfredo Guisado no seu ensaio memorialístico:

Encantadora a reprodução dos cruzeiros no seu curioso livro "As cruces de pedra da Galiza" em que ele aponta, um a um, esses inconfundíveis monumentos populares de fé e de suavidade que se erguem nas serenas encruzilhadas dessa hoje tão visitada região. Acompanhaas um interessante relato que fala $\mathrm{da}$ ingenuidade dos escultores desconhecidos (...) que deixaram vincada a sua passagem pelos caminhos daquela terra, como na nossa, onde a palavra saudade tem nesses mesmos monumentos de sabor primitivo, uma indispensável presença (1958, p.9. Destacados meus).

Ao pensar nas relações dialógicas que impregnam todo e qualquer discurso, não se pode deixar de comentar que ao falar do Outro - no caso, a poética de Castelao - Alfredo Guisado acaba por falar também de si, uma vez que comunga com o "genial artista galego" muitos valores estéticos e ideológicos. Não se pode deixar de mencionar o imagotipo da fraternidade luso-galaica presente nesse discurso: "caminhos daquela terra, como na nossa, onde a palavra saudade tem nesses mesmos monumentos de saber primitivo, uma indispensável presença”. A mesma metodologia comparativa dos monumentos e das paisagens humanas (galegos e bretões no caso de Castelao) faz parte do estudo de Alfredo Guisado, com relação aos monumentos e paisagens humanas (portugueses e galegos). Cada um dos artistas compara as paisagens da sua pátria com a de outra cultura, como se verifica mais na carta de Guisado a Augusto Cunha, ao estudar as cantigas populares galegas, comparando-as com as portuguesas. Os monumentos "populares" e "primitivos" estão impregnados, conforme o ensaísta, da presença da saudade, elemento fundamental na poesia e no ensaio de Teixeira de Pascoaes (1978, p.95), que fornece a base na dialética LembrançaEsperança, a muitos artistas galegos.

\section{CONSIDERAÇÕES FINAIS}

A poética de Alfredo Guisado passa, durante o seu longo arco temporal que vai de 1912 a 1975, por várias metamorfoses discursivas, ocorridas devido às relações dialógicas estabelecidas com os demais membros da geração de Orpheu em Portugal e com os artistas galegos que pertenceram aos grupos das Irmandades da Fala e da Xeración Nós, como 
Otero Pedrayo, Vicente Risco e Castelao, este último responsável pela capa do poemário galego de Guisado intitulado Xente d'a aldea. Verifica-se, pois, em cada um dos poetas de Orpheu o que Dionísio Vila Maior chama de "condição intertextual e dialógica dos discursos literários” (1996, p.65).

No caso específico do autor de Xente d'a aldea, alguns fatores colaboraram para a intensificação de suas relações dialógicas com escritores portugueses e galegos, dos quais foram destacados no presente artigo4: a) a aproximação com muitos intelectuais galegos dos grupos das Irmandades da Fala e da Xeración Nós, atestado no seu discurso crítico-memorialístico nas páginas do periódico lisboeta República; b) a disponibilidade para a leitura e a apreciação crítica das obras que lhe iam sendo enviadas, quando esteve responsável pela página literária do jornal República.

Conforme dados manejados por Carlos Pazos Justo, verifica-se que a historiografia e a crítica literária portuguesas, quando examinam a produção literária de Alfredo Guisado, fazem-no sempre em função das poéticas de Fernando Pessoa e Mário de SáCarneiro, destacando os poemários Elogio da paisagem (1915) - talvez em função da recensão crítica feita por Pessoa na revista Exílio

\footnotetext{
${ }^{4}$ Publiquei em Portugal outros artigos em que abordo os aspectos relacionados a: a) as ligações familiares com a Galiza e as viagens do então jovem Alfredo Guisado por terras galegas; b) a participação de Guisado em movimentos sindicalistas-agraristas tanto na colônia galega em Lisboa como na região dos seus pais; c) a publicação de alguns textos literários nos periódicos galegos A Nosa Terra e Nós. Outro aspecto fundamental da poética guisadiana refere-se à tomada de posição em discursos em prol dos agricultores e de denúncia das relações de exploração no campo feitas no periódico agrarista-sindicalista El Tea, e que será abordado em futuras publicações.
}

-, As treze baladas das mãos frias (1916), Mais alto (1917) e Ânfora (1918), enfeixados em 1969 na edição Tempo de Orfeu. A historiografia e a crítica destacam, pois, os poemários do tempo em que Alfredo Guisado esteve mais próximo dos companheiros de aventura órfica, esquecendo-se, porém, que sua produção literária não se circunscreve apenas a esse período, nem tampouco se silencia após a publicação de As cinco chagas de Cristo (1927).

No longo interregno que vai de 1927 após a publicação do poemário As cinco chagas de Cristo - até 1969 - quando instado por amigos, resolve reeditar os livros do período órfico - Alfredo Guisado não se distanciou dos problemas políticos e sociais de Portugal e da Galiza, as “duas terras” (GUISADO, 1913, p.65), a princípio com elementos inconciliáveis no início da sua produção literária. Pelo contrário, como diretor da página literária do jornal República desde 12 de fevereiro de 1943 e diretor adjunto do periódico desde 3 de abril de 1954, Alfredo Guisado escreveu recensões críticas acerca de estudos literários e históricos que iam surgindo em Portugal, textos memorialísticos acerca da geração de Orpheu e também, comentários sobre a história da literatura galega e estudos críticos sobre autores galegos como Rosalía de Castro e Castelao, alguns deles comentados neste artigo. Nota-se, pois, nos vários textos aqui analisados, as relações dialógicas e interculturais desenvolvidas por Alfredo Guisado entre Portugal e Galiza, reforçando um dos objetivos das Irmandades da Fala, que completa cem anos em 2016: a aproximação linguística, literária e cultural das nações separadas pelo rio Minho. 


\section{REFERÊNCIAS BIBLIOGRÁFICAS}

ALONSO, Manuel Rodríguez. "Relendo Cantares gallegos. O primeiro poema en galego de Rosalía”. In: Bouvard e Pécuchet. Crítica arbitraria de libro s e outros obxectos impresos. Disponível em http://bouvard. blogaliza.org/2012/12/02/relendo-cantaresgallegos/ Acesso em: 10.07.2016.

BAKHTIN, Mikhail. O discurso na poesia e o discurso no romance. In: Questões de

literatura e estética: a teoria do romance. São Paulo: UNESP/HUCITEC, 1998. pp.85-106.

. Problemas da póetica de Dostoiévski.

Trad. Paulo Bezarra. $5^{\text {a }}$ ed. Rio de Janeiro: Forense Universitária, 2015.

CARRERA, Alejo. Crónica de Lisboa. Asamblea agraria importante. In: El Tea, Vigo, 12 Mar. 1915.p.1.

CASTELAO, Alfonso Rodríguez. Cousas. Vigo: Galaxia, 2005.

FIORIN, José Luiz. "Polifonia textual e discursiva”. In: BARROS, Diana Luz Pessoa; . (orgs.). Dialogismo, polifonia, intertextualidade: em torno de Bakhtin. São Paulo: Edusp, 1999. (Ensaios de Cultura, 7). pp.29-36

GUISADO, Alfredo. Comentário. In: República, Lisboa, 3 Mar. 1943. p.3

. Comentário. In: República, Lisboa, 25

Jan. 1944. pp.1 e 6.

. Evoca-se um genial artista galego. In:

República, Lisboa, 3 Fev. 1958. pp.1 e 9.

GUISADO, Alfredo Pedro. Rimas da noite e da tristeza. Lisboa: Livraria Clássica Editora, 1913. JUSTO, Carlos Pazos. Relações culturais intersistémicas no espaço ibérico. $\mathrm{O}$ caso da trajetória de Alfredo Guisado (1910-1930). V. N. Famalicção: Húmus, 2015.
LOPES, Óscar. História ilustrada das grandes literaturas. Literatura Portuguesa. Lisboa: Estúdios Cor, 1966, v.VIII.

MAIOR, Dionísio Vila. Introdução ao Modernismo. Coimbra: Almedina, 1996.

PASCOAES, Teixeira de. Arte de ser Português, Lisboa, Delraux, 1978

PÉREZ, Xosé Carlos Valle. Castelao e as cruces de pedra. Pontevedra: Museo de Pontevedra, 1999.

Castelao en Bretaña. Pontevedra:

Museo de Pontevedra, 2004.

ROSENFELD, Anatol. Reflexões sobre o romance moderno. Texto/contexto $I .5^{a}$ ed. São Paulo: Perspectiva, 1996. pp.75-97.

SÁNCHEZ, Anxo Gómez; ZAS, Mercedes Queixas. Historia xeral da literatura galega. Vigo: Edicións A Nosa Terra.

Recebido para publicação em 30 nov. 2016. Aceito para publicação em 20 dez 2016. 